\title{
On the Dynamical Stability of Polar Vortex in Wintertime*
}

\author{
By T. Matsuno and I. Hirota \\ Geophysical Institute, Tokyo University, Tokyo \\ (Manuscript received 26 January 1966, in revised form 5 March, 1966)
}

\begin{abstract}
The breakdown of the polar vortex in the stratosphere is considered as a barotropic instability process of an irregularly shaped vortex.

Numerical tests are carried out based on the observed height patterns of $50 \mathrm{mb}$ level in the cases of 15 November 1957, 15 January 1958, and 20 January 1958 as initial value problems for artificially introduced small disturbances.

Kinetic energy of disturbances remains constant for the former two, but in the case of 20 January 1958, just a few days before the occurrence of breakdown, the kinetic energy increases. The patterns of disturbance thus computed were similar to the observed height changes for the latter two cases.
\end{abstract}

\section{Introduction}

Since the I.G.Y. period, we have gained much information about the general circulation of the stratosphere. Above all, one of the most interesting phenomena is the drastic variation of the polar vortex in late winter or in early spring. This event has two aspects. One is the breakdown of the polar vortex and the other is the explosive warming in the upper stratosphere.

Concerning the breakdown accompanied with the explosive warming, theoretical investigations from the view point of the instability theory have been made by many authors. Murray (1960) investigated two possibilities of the breakdown; one is the inertial instability and the other is the baroclinic instability. His conclusion is that neither of these instabilities are possible in the lower stratosphere, then he suggested a possibility of barotropic instability. Charney and Stern (1962) have also discussed this kind of instability. They found that the instability criterion is satisfied in the actual atmosphere in wintertime when the horizontal wind shear is sufficiently large. This criterion is, however, not a sufficient condition but a necessary one.

Moreover these treatments of instability

* Division of Meteorology, Contribution No. 147 theory have one common defect. Namely, the instability criterion is given only to the circular flow patterns, whereas in the actual atmosphere the circumpolar vortex is not completely circular but shows asymmetric features, especially in late winter. The deformation of the polar vortex in late winter might be maintained by the topographical effect and the differential heating over the continents and oceans. Under such conditions the zonally averaged wind field may not possess much meanings and the theories of hydrodynamic instability for a circular vortex could not be applied.

Thus the following two points are emphasized :

(a) In late winter, after the elongation of the polar vortex, a quasi-steady state exists, which is considered to be balanced with large scale external forces (i.e., topographical effect and heating or cooling due to external heat sources). Thus the elongated stream pattern is considered to be the basic state the and the stability must be defined with respect to this asymmetric polar vortex.

(b) The criterion for instability of this state may be different from that of the zonally averaged one. The breakdown of polar vortex in late winter might be the result of this complicated instability condition for an asymmetric vortex. 
It is very difficult to discuss mathematically the generalized stability properties of vortex of arbitrary shape, as an eigenvalue problem, like as the stability theories of parallel flows (Kuo, 1949).

In this paper numerical calculations are carried out as initial value problems based on the observed flow patterns of $50 \mathrm{mb}$ in wintertime from 1957 to 1958.

\section{Numerical calculations}

\section{2-1. Model and assumptions}

As we mentioned above, it is assumed that there exists a basic wind field expressed by the stream function $\bar{\phi}$, which is considered to be balanced with an external forcing function $F$. Therefore the vorticity equation with respect to the basic flow is written as:

$$
J\left(\bar{\phi}, \nabla^{2} \bar{\psi}+f\right)=F .
$$

Then the linearized perturbation equation is written as

$$
\frac{\partial}{\partial t} \nabla^{2} \psi^{\prime}+J\left(\bar{\phi}, \nabla^{2} \psi^{\prime}\right)+J\left(\psi^{\prime}, \nabla^{2} \bar{\phi}+f\right)=0,
$$

where $\phi^{\prime}$ is the perturbation stream function superposed on the basic field and is assumed to be free from external forces. This perturbation equation is solved as an initial value problem with respect to the disturbance $\phi^{\prime}$.

In order to obtain the field of $\bar{\phi}$ from the observed geopotential height $\phi$, the geostrophic approximation is used.

Finite difference computations of the perturbation equation are carried out on a Cartesian coordinate grid system. The grid size $\Delta x$ is about $600 \mathrm{~km}$ and number of grid points is $25 \times 25$. This grid system covers the hemisphere from the north pole to $23^{\circ} \mathrm{N}$. Mapping factor $m^{2}$ is not included in this computation for the sake of simplicity, but even such rough treatments may be enough to describe the behavior of ultra long waves in middle and higher latitudes.

It is expected that if we carry out the time integration of the perturbation equation starting from a random distribution of the initial disturbance $\psi^{\prime}$, the most preferred wave will appear. The pattern thus selected can be interpreted as something like the eigenfunction of the largest growth rate.
If the cause of the breakdown is a barotropic instability process, this pattern should be compared with the observed daily changes of flow patterns.

In practice, a flow pattern of wave number 2 is adopted as the initial disturbance for the sake of convenience (Fig. 1). But it is found that the choice of initial perturbations does not affect the results so much.

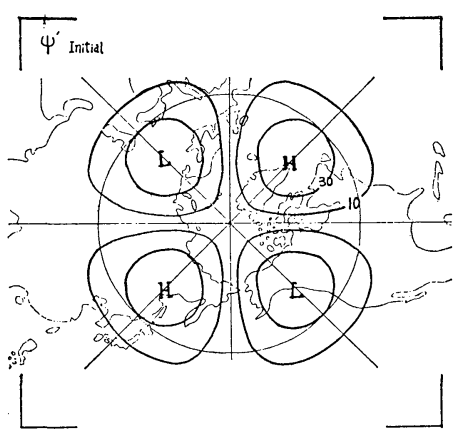

Fig. 1. Initial disturbance superposed on the basic field.

\section{2-2. Results of numerical calculations}

Three cases are chosen from observed height patterns at $50 \mathrm{mb}$ in wintertime from 1957 to 1958.

The results of numerical calculations are shown in Figs. 2, 3 and 4. The time changes of total kinetic energy of disturbances are shown in Fig. 5.

These results are summarized as follows; (a) 15 November 1957

As is shown in Fig. $2 \mathrm{~b}-2 \mathrm{e}$, the disturbance does not grow up and the total kinetic energy $K^{\prime}$ decreases very gradually. In lower latitudes, the phase velocity of Rossby wave, $c=U-\beta L^{2} / 4 \pi^{2}$, becomes negative because of large $\beta L^{2}$, then vortices are cut off and move westward. The waves in higher latitudes, however, do not move and their shape is conserved. Amplitude of perturbation decreases gradually.

From the results of this computation, it is concluded that the basic flow of 15 November is barotropically very stable. This fact is consistent with the observations i.e., very little height changes occurred during this period.

Although this case is only one example in early winter, the characteristic feature of this season would be almost the same as that of 


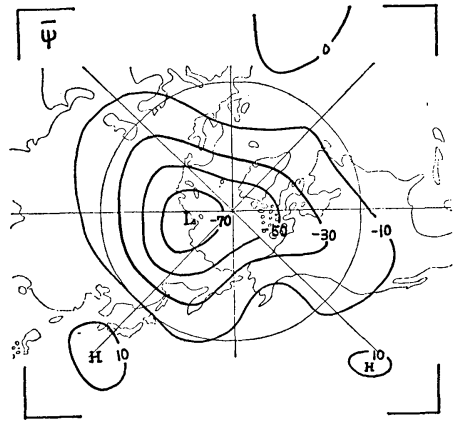

(a)

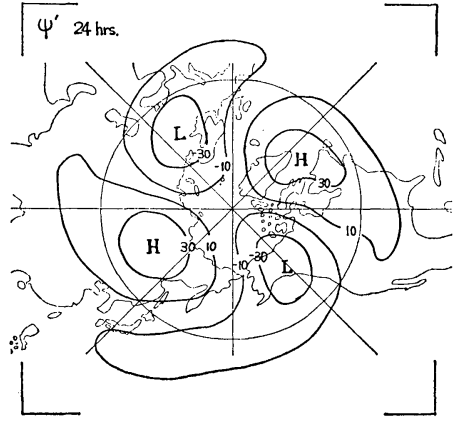

(b)

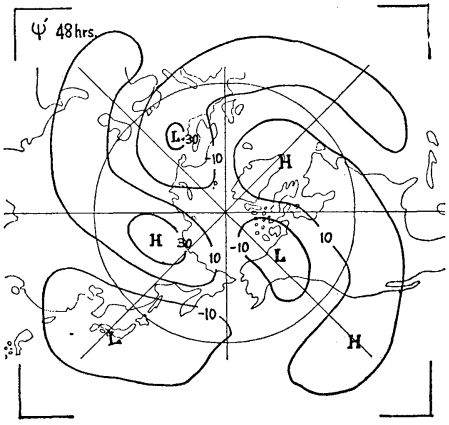

(c)

Fig. 2a. Basic stream function; calculated from the observed height pattern of $50 \mathrm{mb}, 15$ November 1957.

Fig. 2b-2e. Time evolutions of disturbance Unit is arbitrary.

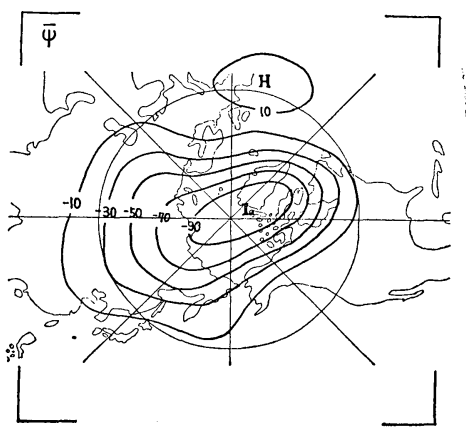

(a)

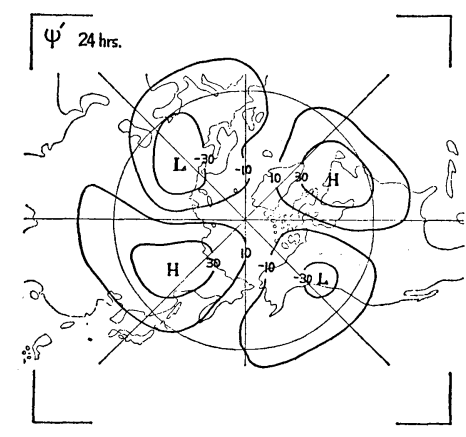

(b)

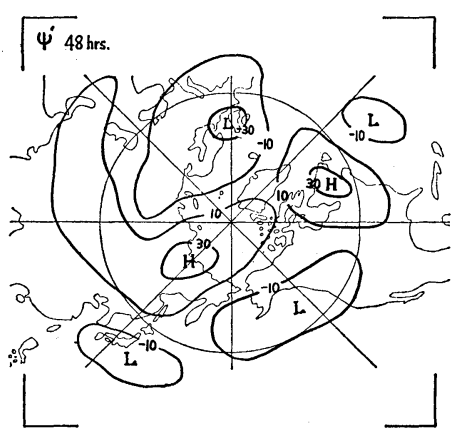

(c)

Fig. 3a. Basic stream function; calculated from the observed height pattern of $50 \mathrm{mb}, 15$ January 1958.

Fig. 3b-3e. Same as Fig. 2 but in the case of

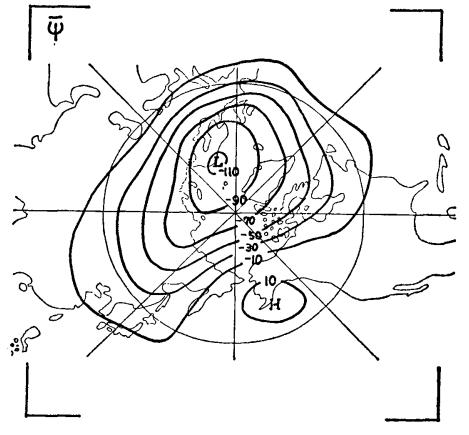

(a)

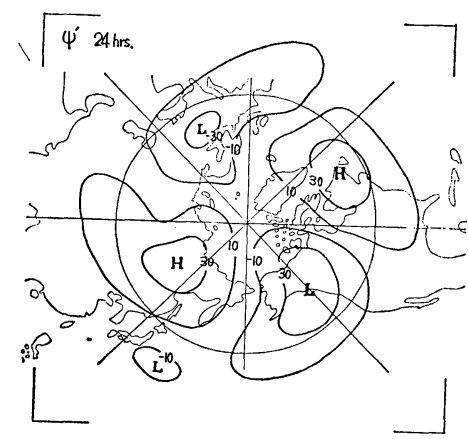

(b)

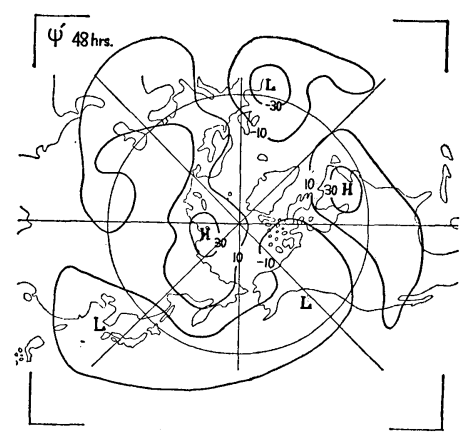

(c)

Fig. 4a. Basic stream function; calculated from the observed height pattern of $50 \mathrm{mb}, 20$ January 1958.

Fig. $4 \mathrm{~b}-4 \mathrm{e}$. Same as Fig. 2 but in the case of 


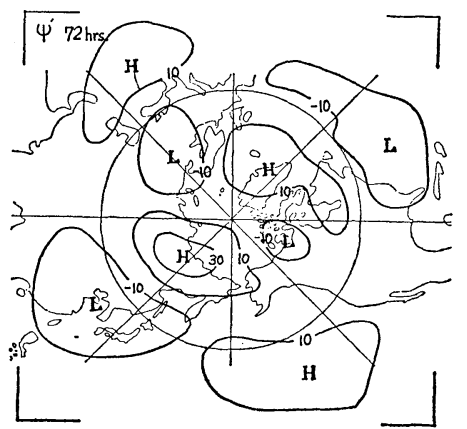

(d)

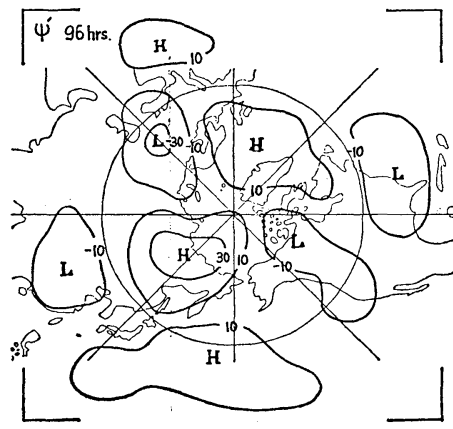

(e)

in the case of 15 November 1957.

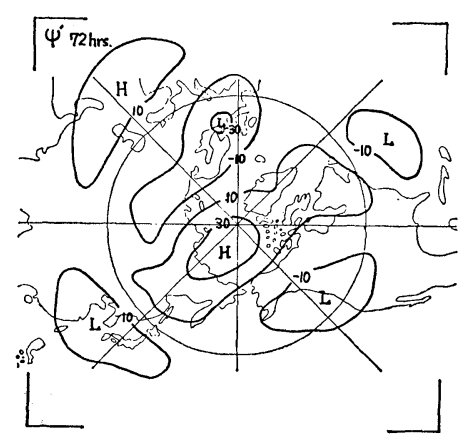

(d)

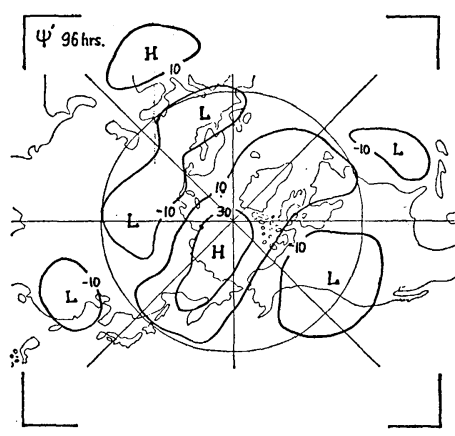

(e)

15 January 1958.

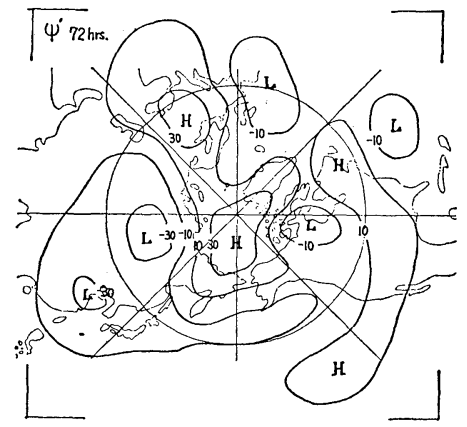

(d)

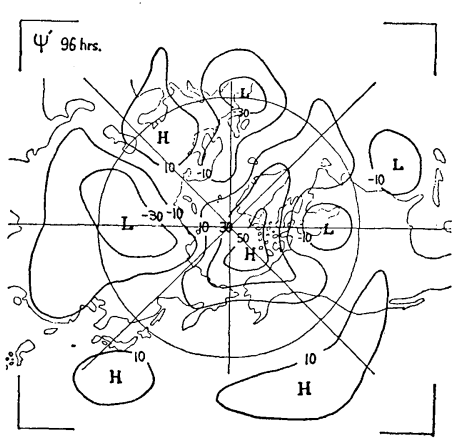

(e)

20 January 1958.

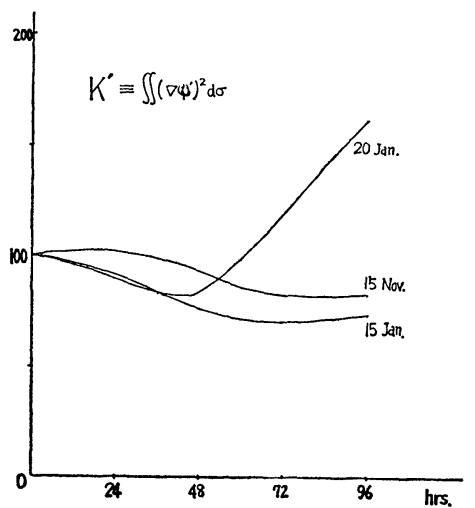

Fig. 5. Time change of kinetic energy of disturbance.

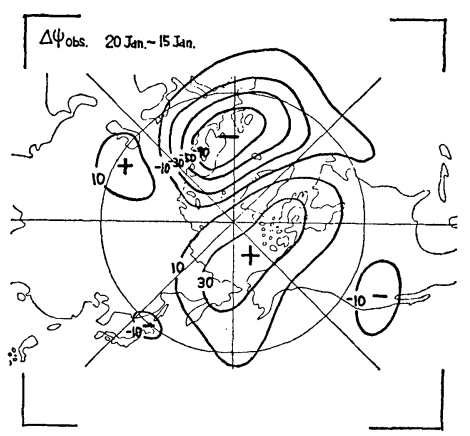

Fig. 6. 5 day difference of observed stream function. 15 January to 20 January 1958.

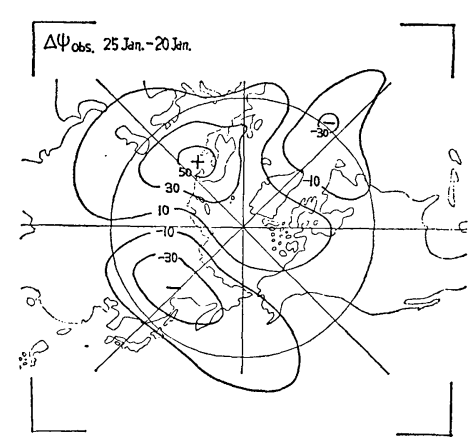

Fig. 7. 5 day difference of observed stream function. 20 January to 25 January 1958. 
this case.

(b) 15 and 20 January 1958

These two cases are chosen as examples of late winter just before the occurrence of sudden warming. In the first case, 15 January, the introduced disturbance does not grow so much. Concerning the wave pattern, however, the disturbance of wave number 2 disappears and the disturbance of larger scale is selected. This situation becomes to be predominant in 3 or 4 days as is shown in Fig. 3. The disturbance thus selected is very similar to the observed 5 day difference shown in Fig. 6, especially in higher latitudes.

This aspect becomes more clear in the case of 20 January. As time goes on, the most preferred disturbance to the basic flow appears as is shown in Figs. $4 \mathrm{~b}-4 \mathrm{e}$, moreover the total kinetic energy $K^{\prime}$ is increased rapidly. The damping of $K^{\prime}$ in the first two days is interpreted as the rearranging process of the initially introduced disturbance to the preferred one. The pattern selected in this case is also in good agreement with the observed 5 day difference pattern shown in Fig. 7.

It appears that the disturbances thus obtained in the time integration do not depend upon the initially introduced perturbation since the resultant pattern is very different from the initial one.

From these computations, it can be concluded that the basic flow patterns of these two cases, especially the latter, are dynamically unstable in the sense of barotropic instability. Accordingly the breakdown of polar vortex can be explained as the barotropic instability, at least in the case treated in this work.

Moreover it should be pointed out that this instability appears prior to the occurrence of sudden warming.

It is not the result of warming.

\section{2-3. Discussion}

Now the results of the numerical calculations give rise to several questions. Firstly what is the criterion of instability with respect to the asymmetric vortex? In other words, what is the difference between the basic flow in early winter and that in late winter?

The zonal average of relative vorticity and the Coriolis parameter $f$ are shown in Fig. 8.

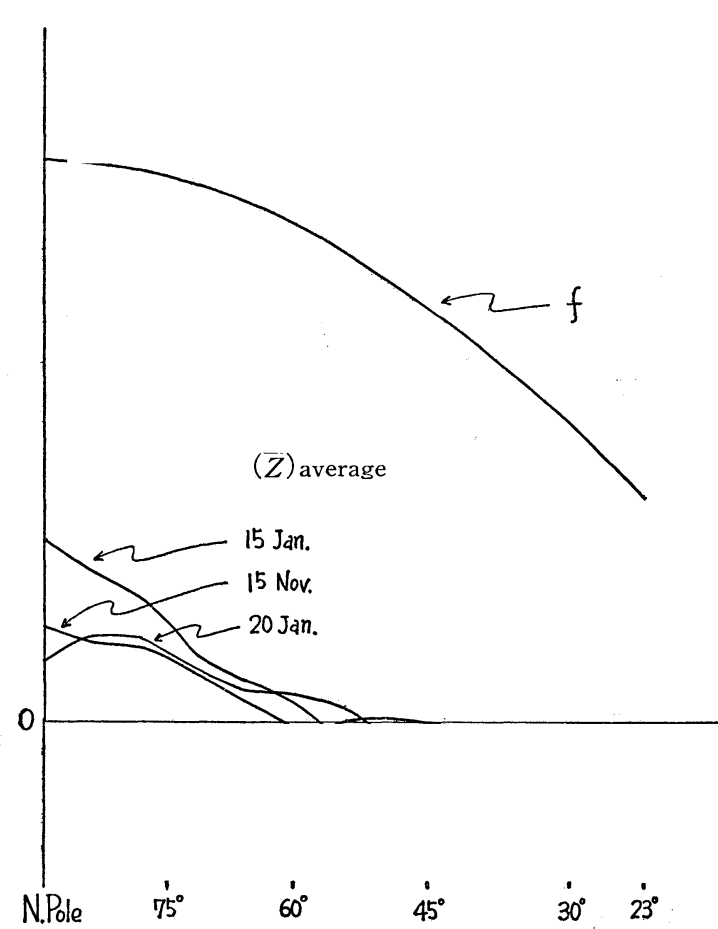

Fig. 8. Colioris factor $f$ and zonal average of vorticity.

N.Pole $\quad 7^{\circ} \quad 60^{\circ} \quad 45^{\circ} \quad 30^{\circ} \quad 23^{\circ}$

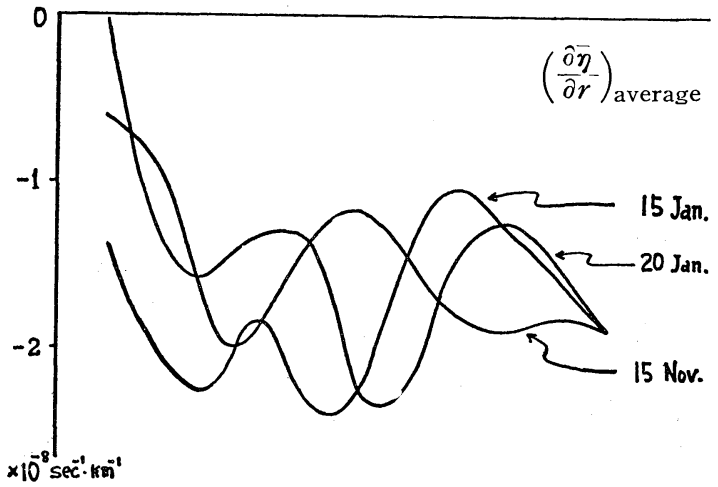

Fig. 9. Zonal average of gradient of absolute vorticity in the meridional direction.

In Fig. 9, the zonal average of gradient of absolute vorticity in the meridional plane, $\partial \bar{\eta} / \partial r$, is also shown. From these figures it can be seen that the averaged $\partial \bar{\eta} / \partial r$ does not change its sign within the region from the north pole to lower latitudes. It means that 
the Rayleigh's criterion for instability is not satisfied with respect to the zonally averaged vorticity distribution. On the other hand, the value of $\partial \bar{\eta} / \partial r$ changes its sign in a particular meridional section. In order to make it clear, the horizontal distribution of absolute vorticity is shown in Fig. 10. In the case of early winter the distribution of absolute vorticity is not so different from

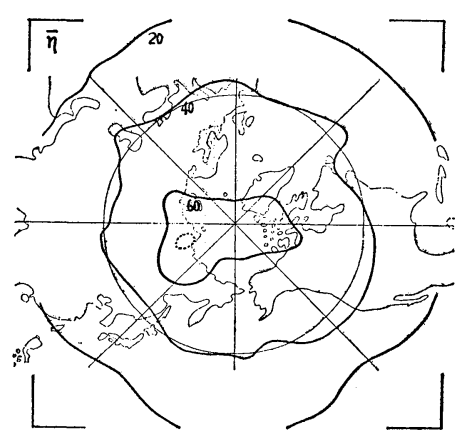

(a)

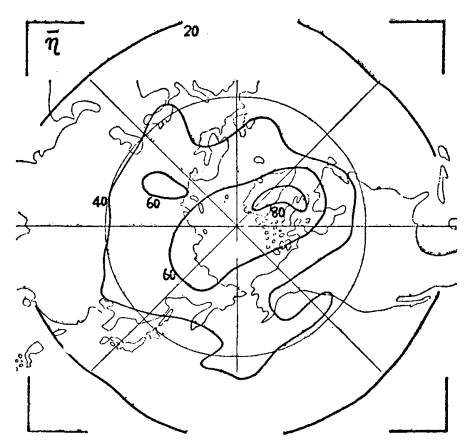

(b)

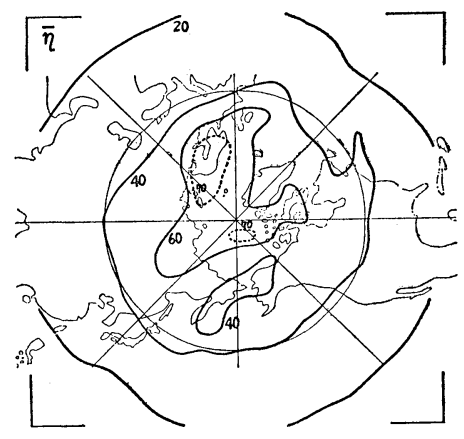

(c)

Fig. 10. Horizontal distributions of absolute vorticity (a) 15 November 1957, (b) 15 January 1958, (c) 20 January 1958 (Unit in $2.0 \times 10^{-6}$ $\left.\sec ^{-1}\right)$ circular symmetry, and only one maximum value of $\bar{\eta}$ appears near the north pole. In the cases of late winter, however, the distribution differs from the circular symmetry and double maxima of $\eta$ are found in higher latitudes.

Another problem is the relationship between velocity change and temperature change. As is illustrated in Figs. 11-12, observation shows that the pattern of the temperature change and that of the height change (Figs. 6,7) are very well correlated.

It is supposed that the temperature change was caused by the change of the wind field. In the stratosphere, the static stability is so large that the pressure change may tend to follow the velocity change. Therefore, as the first approximation, we may use the barotropic vorticity equation for describing the behavior of stratospheric disturbances. This situation may be compared to the use of the equivalent barotropic model for describing tropospheric disturbances.

Our supposition is that the rapid tem-

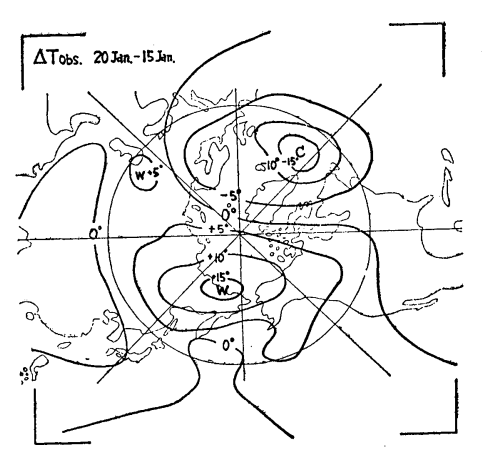

Fig. 11. 5 day difference of observed temperature at $50 \mathrm{mb} .15$ to 20 January 1958.

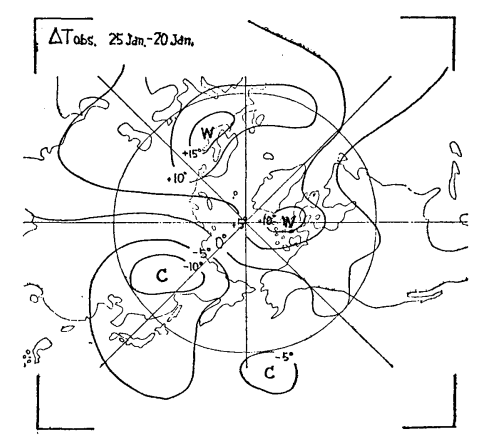

Fig. 12. 5 day difference of observed temperature at $50 \mathrm{mb} .20$ to 25 January 1958. 
perature change in the stratosphere is rather the consequence of adjustment process of pressure field to the breakdown, which is mainly controlled by the barotropic instability.

\section{Conclusions and remarks}

Stability properties of the stratospheric polar vortex are examined by applying the barotropic vorticity equation to the flow field at the $50 \mathrm{mb}$ level. Conclusions obtained in this study are as follows :

(a) The breakdown of the polar vortex in late winter could be explained as the barotropic instability of a deformed vortex. This kind of instability cannot be detected from the zonally averaged values of vorticity distribution.

(b) It was found that the actual change of height pattern at $50 \mathrm{mb}$ is in good agreement with the calculated one, which may be the most unstable eigensolution of given basic flow pattern.

(c) The unstable situation appears a few days before the occurrence of sudden warming in the upper stratosphere, so that the instability is not a result of warming.

We have considered that the growth of eddy kinetic energy in the case of 20 January is attributed to the unstable configuration of basic field, in the sense of ordinary hydrodynamic instabilities. However, it may be possible to explain this result in terms of the difference of the characteristic scales of the basic field and the eddies, i.e., the charac- teristic scale of the basic field of 20 January was small and therefore the energy of the basic field was transfered to that of the eddy motions. From our computations, we cannot decide as yet which reasoning is more suitable for the interpretation of the results presented in this paper.

Finally it should be remarked that, though the breakdown of the polar vortex in 1958 is very typical one, the feature of the breakdown differs from year to year. Therefore other mechanisms may also exist as the cause of rapid deformation of polar vortex in late winter and early spring.

\section{Acknowledgments}

The writers wish to express their hearty thanks to Prof. S. Syôno and Dr. M. Yanai of the Geophysical Institute, Tokyo University, for their encouragement and advices throughout this work.

Thanks are also due to Dr. K. Mohri of the Japan Meteorological Agency who provided the writers with the convenience to use the computing machine, IBM 704.

\section{References}

Charney, J.G., and M.E. Stern, 1962: On the stability of internal baroclinic jets in a rotating atmosphere. J. atmos. Sci., 19, 159-172.

Kuo, H.L., 1949 : Dynamic stability of two-dimensional non-divergent flow in a barotropic atmosphere. J. Meteor., 6, 105-122.

Murray, F.W., 1960: Dynamic stability in the stratosphere. J. geophys. Res., 65, 3273-3305.

\title{
冬期成層圈における Polar Vortex の力学的安定性について
}

\author{
松 野 太 郎・廣田勇
}

束京大学理学部地球物理学教室

成層圈飞拈けるPolar Vortexの Breakdown を, 不規則な形状をした渦の順圧不安定によるものと解秋してみた。 15 Nov. 1957, 15 Jan. 及び 20 Jan. 1958 の三例飞ついて $50 \mathrm{mb}$ 高度の観测值を定常な基本流とし, これ飞小 さな擾乱を加えて初期值問題として数值計算を行なった。

擾乱の運動エネルギーは前 2 例飞ついては，ほぼ一定と保たれるが，最後の例（突然㫒温の 2,3 日前）飞ついて は，急速飞增大する。

数值計算による䍐乱の発達のパターンは，後 2 例とついては実際の変化とよく似ている。 